\title{
Adoptive immunotherapy shows encouraging benefit on non-small cell lung cancer: a systematic review and meta-analysis
}

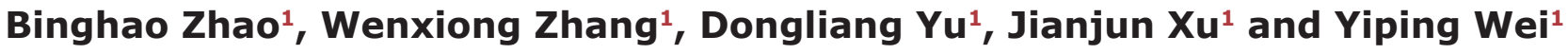 \\ ${ }^{1}$ Department of Thoracic Surgery, The Second Affiliated Hospital of Nanchang University, Nanchang, China \\ Correspondence to: Wenxiong Zhang, email: zwx123dr@126.com
}

Keywords: non-small cell lung cancer, adoptive immunotherapy, meta-analysis

Received: April 25, $2017 \quad$ Accepted: July 06, $2017 \quad$ Published: July 19, 2017

Copyright: Zhao et al. This is an open-access article distributed under the terms of the Creative Commons Attribution License 3.0 (CC BY $3.0)$, which permits unrestricted use, distribution, and reproduction in any medium, provided the original author and source are credited.

\section{ABSTRACT}

Although adoptive immunotherapy (AIT) is a novel emerging target treatment for non-small cell lung cancer (NSCLC), its actual efficacy remains controversial. In this meta-analysis, we aimed to evaluate the efficacy of AIT for NSCLC. We systematically searched PubMed, the Cochrane Library, EMBASE, Medline, and Web of Science for relevant parallel randomized controlled trials (RCTs) and high-quality observation studies of AIT without any language restrictions. Two investigators reviewed all the texts and extracted information regarding overall survival rate (OS), progression-free survival rate (PFS), objective response rate (ORR), and disease control rate (DCR) from eligible studies; sensitivity analyses and subgroup analyses were also conducted to reduce heterogeneity

Of 319 suitable studies, 15 studies ( 13 RCTs and 2 observation studies) involving 1684 patients were finally included. Compared to the Control therapy (CT) group, the AIT group exhibited better 1-year OS $(P=0.001)$, 2-year OS $(P<0.001)$, 3-year OS $(P<0.001)$, 5-year OS $(P=0.032)$, 1-year PFS $(P<0.001)$, and 2-year PFS $(P=0.029)$. The difference in the ORR $(P=0.293)$ and $D C R(P=0.123)$ was not significant between the groups. The subgroup analysis showed that DC/CIK did more benefit to NSCLC patients than LAK and the cycles not associated with AIT efficacy.

AIT can significantly improve the OS and PFS with acceptable toxicity for NSCLC. Nevertheless, further multicenter studies are needed to confirm our conclusion and determine which adoptive immunotherapy is associated with the greatest efficacy.

\section{INTRODUCTION}

Non-small cell lung cancer (NSCLC) is one of the most common malignant tumors and accounts for $80-85 \%$ of all cases of lung cancer [1]. In the United States, the mortality due to lung cancer is the highest among all cancers. Although marked progress has been made in surgery, radiotherapy, and chemotherapy for NSCLC, the 5 -year overall survival rate (OS) remains unsatisfactory (approximately 15\%) [2]. Hence, researchers are currently seeking to improve the long-term OS rate of NSCLC after surgery or advanced NSCLC. Immunotherapy plays an effective and beneficial role in several malignant tumors that activate our immune system to produce an anti-tumor effect. Advanced research in immunotherapy led to the development of adoptive immunotherapy (AIT), which has major benefits and potential for further enhancement. AIT involves the transfusion of activated lymphocytes or lymphocyte products to cancer patients to enhance the patient's immunity and anti-tumor ability [3]. There are various types of AIT methods and marked heterogeneity in the effector cells used, including natural killer cells (NK), cytotoxic T lymphocytes (CTL), lymphokineactivated killer cells (LAK), cytokine-induced killer cells (CIK), dendritic cells (DC), and tumor infiltrating lymphocytes (TIL) [4]. However, the efficacy of AIT remains controversial. Therefore, in the present study, we systematically searched parallel randomized controlled trials (RCTs) and conducted a systematic review and meta-analysis to evaluate the efficacy of AIT for NSCLC patients, in order to provide an objective reference for clinical decision making. 


\section{RESULTS}

Of the 319 studies searched in this meta-analysis, we finally included 15 studies [5-19]; the selection process is described in Figure 1.

The characteristics of the 15 included studies (1684 patients) are described in Table 1, and the outcome data are presented in Table 2. Of the 15 studies, 13 [1-7, 9, 11-15] were parallel RCTs and the other $2[8,10]$ were prospective cohort studies. As for pre-treatment, 7 [5-8, $10,16,18]$ studies included patients with pre-surgery, 2 $[17,19]$ studies included patients with chemotherapy, 1 [9] study included patients with surgery or chemotherapy or radiotherapy. With regard to the AIT regimen, 3 studies $[5,7,8]$ used LAK plus IL-2 (or rIL-2), 7 studies [10-11, 14-19] used DC/CIK, 2 studies [9, 13] used CIK alone, 2 studies $[12,18]$ used activated killer T cells (AKT) alone, and 1 study [6] used TIL alone. The regimen involved $>4$ cycles in 8 studies $[5-7,9,12,13,18,19]$ and $\leq 4$ cycles in 4 studies $[10,11,14,16]$. The precise cycle was not described in 1 study [8] and we could not determine whether the cycles were more than, equal to, or less than 4 in 2 studies [15, 17]. All the studies included Asian participants, except for 1 study [6].

The risk and bias assessments [20] of the included RCTs and observation studies are described in Table 3.

\section{1-year OS}

Fifteen studies [5-19], involving 1684 patients (AIT group: $n=779$; Control therapy [CT] group: $n=905$ ), were included in this analysis (Figure 2). High heterogeneity was observed $\left(P=0.001, \mathrm{I}^{2}=62.9 \%\right)$, and a random-effects model was used. We found that the 1-year OS was better in the AIT group than in the CT group (95\% confidence interval $[\mathrm{CI}], 1.06-1.26 ; P=0.001$ ).

\section{2-year OS}

Thirteen studies [5-16, 18], involving 1548 patients (AIT group: $n=730$; CT group: $n=818$ ), were included in this analysis (Figure 3). High heterogeneity was observed $\left(P=0.099, \mathrm{I}^{2}=35.4 \%\right)$, and a random-effects model was used. We found that the 2-year OS was better in the AIT group than in the CT group $(95 \% \mathrm{CI}, 1.24-1.55 ; P<0.001)$.

\section{3-year OS}

Ten studies [5-8, 10-13, 15, 16], involving 1266 patients (AIT group: $n=590$; CT group: $n=676$ ), were included in this analysis (Figure 4). Low heterogeneity was observed $\left(P=0.337, \mathrm{I}^{2}=11.4 \%\right)$, and a fixed-effects model was used. We found that the 3 -year OS was better in the AIT group than in the CT group $(95 \% \mathrm{CI}, 1.24-1.61 ; P<0.001)$.

\section{5-year OS}

Six studies $[5,7,8,12,13,18]$, involving 925 patients (AIT group: $n=419$; CT group: $n=506$ ), were included in this analysis (Figure 5). High heterogeneity was observed $\left(P=0.01, \mathrm{I}^{2}=75.5 \%\right)$, and a randomeffects model was used. We found that the 5 -year OS was better in the AIT group than in the CT group $(95 \% \mathrm{CI}$, $1.04-2.33 ; P=0.032$ ).

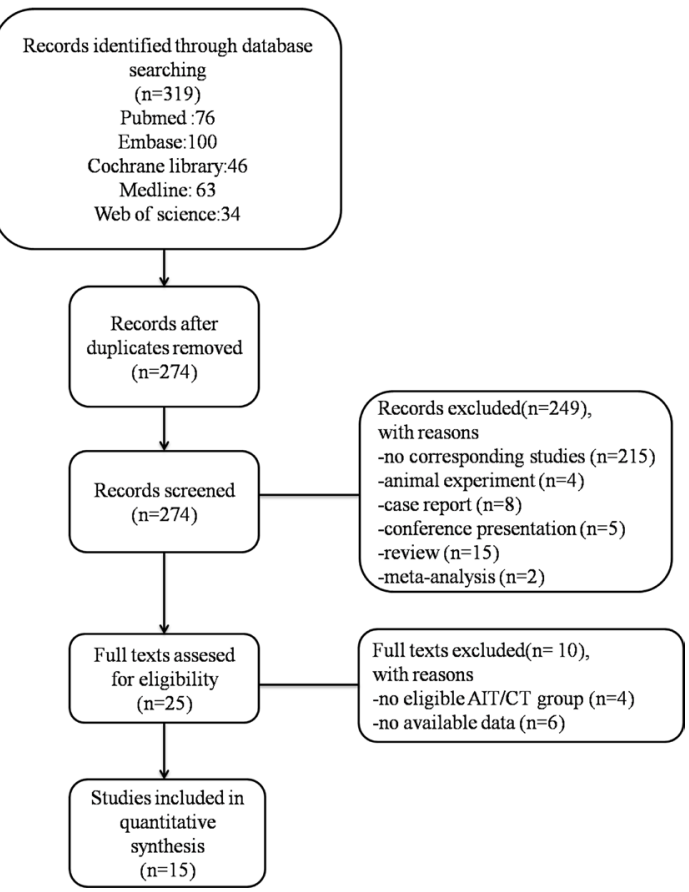

Figure 1: Study selection process. 
Table 1: Characteristics of included studies

\begin{tabular}{|c|c|c|c|c|c|c|c|}
\hline & Study & Region & $\begin{array}{l}\text { Tumor } \\
\text { Stage }\end{array}$ & $\begin{array}{l}\text { Sample } \\
\text { size }(I / C)\end{array}$ & Interventions & Duration & Outcome \\
\hline 1995 & Kimura [5] & Japan & I-IV & $\begin{array}{l}49 \\
52\end{array}$ & $\begin{array}{l}\text { LAK+ IL-2 Immunotherapy } \\
\text { Radiation+ Chemotherapy (cisplatin+ vindesine+ mitomycin) }\end{array}$ & $\begin{array}{l}\text { mean } 6.4 \\
\text { cycles }\end{array}$ & (1) (2) (3) (4) \\
\hline 1996 & Ratto[6] & Italy & II, IIIa, IIIb & $\begin{array}{l}56 \\
57\end{array}$ & $\begin{array}{l}\text { TIL +rIL-2 Immunotherapy } \\
\text { Chemotherapy (vinblastine }+ \text { cisplatin }+50 \text { gray in } 25 \text { fractions) }\end{array}$ & $\begin{array}{l}\text { mean } 6 \\
\text { cycles }\end{array}$ & (1) (2) (3) \\
\hline 1997 & Kimura [7] & Japan & I-IV & $\begin{array}{l}82 \\
88\end{array}$ & $\begin{array}{l}\text { LAK+IL-2 Immunotherapy } \\
\text { no adjuvant therapy }\end{array}$ & $\begin{array}{l}\text { mean } 6 \\
\text { cycles }\end{array}$ & (1) (2) (3) (4) \\
\hline 1999 & Yano [8] & Japan & I-IV & $\begin{array}{l}19 \\
21\end{array}$ & $\begin{array}{l}\text { LAK+rIL-2 Immunotherapy } \\
\text { no adjuvant therapy }\end{array}$ & $\begin{array}{l}\text { not } \\
\text { mentioned }\end{array}$ & (1) (2) (3) (4) \\
\hline 2008 & $\mathrm{Wu}[9]$ & China & IIIa, IIIb, IV & $\begin{array}{l}29 \\
30\end{array}$ & $\begin{array}{l}\text { CIK Immunotherapy+Chemotherapy } \\
\text { Chemotherapy (docetaxel+ cisplatin) }\end{array}$ & $\begin{array}{l}\text { mean } 6 \\
\text { cycles }\end{array}$ & $\begin{array}{l}\text { (1) (2) (5) (7) } \\
\text { (8) }\end{array}$ \\
\hline 2009 & $\operatorname{Li}[10]$ & China & I, II, IIIa & $\begin{array}{l}42 \\
42\end{array}$ & $\begin{array}{l}\text { DC/CIK Immunotherapy }+ \text { Chemotherapy } \\
\text { Chemotherapy ( navelbine+ cisplatin) }\end{array}$ & $\begin{array}{l}\text { mean } 4 \\
\text { cycles }\end{array}$ & $\begin{array}{l}\text { (1) (2) (3) (5) } \\
\text { (6) }\end{array}$ \\
\hline 2011 & Zhong [11] & China & IIIb, IV & 14 & $\begin{array}{l}\text { DC/CIL Immunotherapy+ Chemotherapy } \\
\text { Chemotherapy (platinum) }\end{array}$ & $\begin{array}{l}\text { mean } 4 \\
\text { cycles }\end{array}$ & (1) (2) (3) \\
\hline 2012 & Iwai [12] & Japan & IIIb, IV & $\begin{array}{l}132 \\
207\end{array}$ & $\begin{array}{l}\text { AKT Immunotherapy with simultaneous } \\
\text { Chemotherapy (platinum-containing+ anticancer drugs) }\end{array}$ & $\begin{array}{l}4-6 \\
\text { cycles }\end{array}$ & (1) (2) (3) (4) \\
\hline 2012 & $\operatorname{Li}[13]$ & China & I-IV & $\begin{array}{l}87 \\
87\end{array}$ & $\begin{array}{l}\text { CIK Immunotherapy }+ \text { Chemotherapy } \\
\text { Chemotherapy (paclitaxel gemcitabine navelbine }+ \text { cisplatin) }\end{array}$ & $\begin{array}{l}\text { total } 6 \\
\text { cycles }\end{array}$ & $\begin{array}{l}\text { (1) (2) (3) (4) } \\
\text { (5) (6) }\end{array}$ \\
\hline 2013 & Yang [14] & China & IIIa, IIIb, IV & $\begin{array}{l}61 \\
61\end{array}$ & $\begin{array}{l}\text { DC/CIK Immunotherapy+ Chemotherapy } \\
\text { Chemotherapy (Navelbin }+ \text { Cisplatin) }\end{array}$ & $\begin{array}{l}\text { mean } 4 \\
\text { cycles }\end{array}$ & (1) (2) (7) (8) \\
\hline 2014 & Zhong [15] & China & IIIb, IV & $\begin{array}{l}30 \\
30\end{array}$ & $\begin{array}{l}\text { DC/CIK Immunotherapy+ Chemotherapy } \\
\text { DC/CIK +Chemotherapy (navelbine+ platinum) }\end{array}$ & $2-6$ cycles & $\begin{array}{l}\text { (1) (2) (3) (7) } \\
\text { (8) }\end{array}$ \\
\hline 2014 & Zhao [16] & China & IIIa & $\begin{array}{l}79 \\
78\end{array}$ & $\begin{array}{l}\text { DC/CIK Immunotherapy }+ \text { Chemotherapy (gemcitabine }+ \text { platinum) } \\
\text { Chemotherapy (gemcitabine }+ \text { platinum) }\end{array}$ & $\begin{array}{l}\text { mean } 4 \\
\text { cycles }\end{array}$ & (1) (2) (3) \\
\hline 2014 & Shi [17] & China & IIIb, IV & $\begin{array}{l}28 \\
28\end{array}$ & $\begin{array}{l}\text { DC/CIK Immunotherapy+ Chemotherapy (erlotinib) } \\
\text { Chemotherapy (erlotinib) }\end{array}$ & $\begin{array}{l}\text { at least } 2 \\
\text { cycles }\end{array}$ & (1) \\
\hline 2015 & Kimura [18] & Japan & $\mathrm{Ib}-\mathrm{IV}$ & $\begin{array}{l}50 \\
51\end{array}$ & $\begin{array}{l}\text { AKT/DC Immunotherapy }+ \text { Chemotherapy } \\
\text { Chemotherapy (platinum) }\end{array}$ & $\begin{array}{l}\text { total } 12-15 \\
\text { cycles }\end{array}$ & $\begin{array}{l}\text { (1) (2) (4) (5) } \\
\text { (6) }\end{array}$ \\
\hline 2016 & Zhang [19] & China & IIIa, IIIb, IV & $\begin{array}{l}21 \\
61\end{array}$ & $\begin{array}{l}\text { DC/CIK Immunotherapy+ radiotherapy } \\
\text { radiotherapy }\end{array}$ & $\begin{array}{l}\text { mean } 6 \\
\text { cycles }\end{array}$ & (1) (5) (7) (8) \\
\hline
\end{tabular}

Abbreviations: LAK: lymphokine-activated killer T cells; TIL: tumor infiltrating lymphocyte; CIK: cytokine-induced killer cells; DC: dendritic cells; AKT: activated killer T cells; (r)IL-2: (recomibiant)Interleukin-2. (1): 1-year overall survival rate (OS); (2): 2-year OS; (3): 3-year OS; (4): 5-year OS; (5): 1-year progression-free-survival rate (PFS); (6): 2-year PFS; (7): Objective response rate (ORR); (8): Disease control rate (DCR).

\section{1-year PFS}

Five studies $[9,10,13,18,19]$, involving 519 patients (AIT group: $n=229$; CT group: $n=271$ ), were included in this analysis (Figure 6). Low heterogeneity was observed $\left(P=0.345, \mathrm{I}^{2}=10.7 \%\right)$, and a fixed-effects model was used. We found that the 1-year progression-free survival rate (PFS) was better in the AIT group than in the CT group (95\% CI, 1.23-1.59; $P<0.001)$.

\section{2-year PFS}

Three studies $[10,13,18]$, involving 353 patients (AIT group: $n=173$; CT group: $n=180$ ), were included in this analysis (Figure 7). High heterogeneity was observed $\left(P=0.033, \mathrm{I}^{2}=70.7 \%\right)$, and a random-effects model was used. We found that the 2-year PFS was better in the AIT group than in the CT group (95\% CI, 1.05-2.23; $P=0.029)$.

\section{ORR}

Four studies $[9,14,15,19]$, involving 323 patients (AIT group: $n=141$; CT group: $n=182$ ), were included in this analysis (Figure 8). Low heterogeneity was observed $\left(P=0.398, \mathrm{I}^{2}=0 \%\right)$, and a fixed-effects model was used. The objective response rate (ORR) did not significantly differ between the AIT and CT groups $(95 \%$ CI, 0.85-1.72; $P=0.293$ ).

\section{DCR}

Four studies $[9,14,15,19]$, involving 323 patients (AIT group: $n=141$; CT group: $n=182$ ), were included in 
this analysis (Figure 9). High heterogeneity was observed $\left(P=0.098, \mathrm{I}^{2}=52.4 \%\right)$, and a random effects model was used. The disease control rate (DCR) did not significantly differ between the AIT and CT groups (95\% CI, $0.96-1.40 ; P=0.123)$.

\section{Sensitivity analysis}

To evaluate the influence of single studies and analyze the effects of heterogeneity on the results, a sensitivity analysis was performed to determine the average relative risk (RR) in the absence of each study. If heterogeneity was found to be present, we would consider using the fixed-effects model.

With regard to 1-year OS, when 2 studies [13, 18] were omitted, the heterogeneity ranged from $\left(\mathrm{P}=0.001, \mathrm{I}^{2}=62.9 \%\right)$ to $\left(P=0.38, \mathrm{I}^{2}=6 \%\right)$, whereas the combined RR ranged from $1.16(95 \% \mathrm{CI}, 1.06-1.26$; $P=0.001)$ to $1.22(95 \% \mathrm{CI}, 1.14-1.30 ; P<0.00001)$. With regard to 2-year OS, when 2 studies $[8,10]$ omitted, the heterogeneity ranged from $\left(P=0.099, \mathrm{I}^{2}=35.4 \%\right)$ to $\left(P=0.56, \mathrm{I}^{2}=0 \%\right)$, whereas the combined $\mathrm{RR}$ ranged from $1.38(95 \% \mathrm{CI}, 1.24-1.55 ; P<0.001)$ to $1.44(95 \%$ CI, $1.30-1.60 ; P<0.00001)$. With regard to 5-year OS, when 2 studies [7, 12] were omitted, the heterogeneity ranged from $\left(P=0.001, \mathrm{I}^{2}=75.5 \%\right)$ to $(P=0.22$, $\left.\mathrm{I}^{2}=32 \%\right)$, whereas the combined RR ranged from $1.56(95 \% \mathrm{CI}, 1.04-2.33 ; P=0.032)$ to $1.66(95 \% \mathrm{CI}$, $1.32-2.10 ; P<0.001)$. With regard to 2 -year PFS, when 1 study [18] was omitted, the heterogeneity ranged from $\left(P=0.033, \mathrm{I}^{2}=70.7 \%\right)$ to $\left(P=0.43, \mathrm{I}^{2}=0 \%\right)$, whereas the combined RR ranged from 1.53 (95\% CI, 1.05-2.23;
$P=0.029)$ to $1.31(95 \% \mathrm{CI}, 1.04-1.64 ; P=0.02)$. In terms of the pooled DCR, when 1 study [19] was omitted, the heterogeneity ranged from $\left(P=0.098, \mathrm{I}^{2}=52.4 \%\right)$ to $(P=0.28, \mathrm{I} 2=21 \%)$, whereas the combined RR ranged from $1.16(95 \% \mathrm{CI}, 0.96-1.40 ; P=0.123)$ to $1.27(95 \%$ CI, $1.06-1.52 ; P=0.01)$. As the heterogeneity could not be completely explained via sensitivity analysis, subgroup analyses were also conducted.

\section{Subgroup analysis}

Subgroup analysis was conducted according to the effector cells used (LAK plus IL-2 versus CIK versus DCCIK), number of cycles in the regimen ( $>4$ versus $\leq 4$, the mean cycle length and total cycle length were considered to represent the same level), and nationality (China versus Japan). Subgroup analyses were only performed for 1-year OS and 2-year OS due to the availability of an adequate sample size (Table 4). CIK and DC/CIK significantly enhanced 1-year OS (95\% CI, 1.16-1.59; 95\% CI, 1.09-1.30) and 2-year OS (95\% CI, 1.33-2.24; 95\% CI, 1.10-1.44) compared with LAK plus IL-2 (95\% CI, $0.86-1.21 ; 95 \%$ CI, 0.90-1.86). No specific difference was found in cycle or nationality.

\section{Publication bias}

In the 15 included studies, there was no evidence of publication bias in terms of 1-year OS in NSCLC patients receiving AIT, as suggested by Begg's funnel plots test and Egger's regression test (Begg's $P=0.235$; Egger's $P=0.052$; Figure 10).

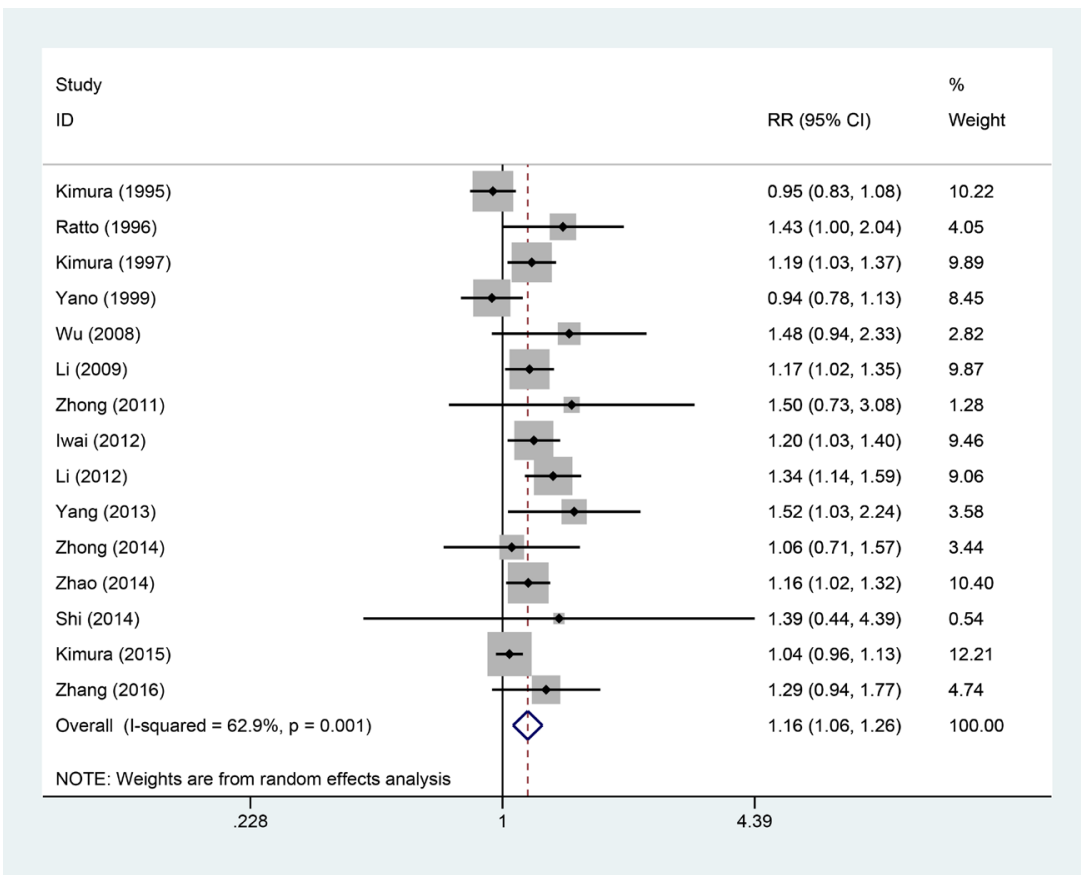

Figure 2: One-year OS between the AIT and CT groups. 
Table 2: Original data extracted from included studies

\begin{tabular}{|c|c|c|c|c|c|c|c|c|c|c|}
\hline Study & & $\begin{array}{l}\text { Sample } \\
\text { size (I/C) }\end{array}$ & $\begin{array}{l}\text { 1-year OS } \\
\text { (Pts, \%) }\end{array}$ & $\begin{array}{l}\text { 2-year OS } \\
\text { (Pts, \%) }\end{array}$ & $\begin{array}{l}\text { 3-year OS } \\
\text { (Pts, \%) }\end{array}$ & $\begin{array}{l}\text { 5-year OS } \\
\text { (Pts, \%) }\end{array}$ & $\begin{array}{l}\text { 1-year PFS } \\
\text { (Pts, \%) }\end{array}$ & $\begin{array}{l}\text { 2-year PFS } \\
\text { (Pts, \%) }\end{array}$ & $\begin{array}{l}\text { ORR (Pts, } \\
\text { \%) }\end{array}$ & $\begin{array}{l}\text { DCR } \\
\text { (Pts, \%) }\end{array}$ \\
\hline \multirow[t]{2}{*}{1995} & Kimura [5] & 49 & $43,87.8 \%$ & $32,65.3 \%$ & $23,46.9 \%$ & $21,42.9 \%$ & 1 & I & 1 & I \\
\hline & & 52 & $39,75.0 \%$ & $22,42.3 \%$ & $15,28.8 \%$ & $9,17.3 \%$ & I & / & I & I \\
\hline \multirow[t]{2}{*}{1996} & Ratto[6] & 56 & $35,62.5 \%$ & $20,35.7 \%$ & $14,25.0 \%$ & I & I & / & I & I \\
\hline & & 57 & $25,43.9 \%$ & $12,21.1 \%$ & $7,12.3 \%$ & l & I & / & / & I \\
\hline \multirow[t]{2}{*}{1997} & Kimura [7] & 82 & $73,89.0 \%$ & $66,75.0 \%$ & $47,57.3 \%$ & $45,54.4 \%$ & I & / & I & I \\
\hline & & 88 & $66,75.0 \%$ & $46,52.3 \%$ & $35,39.8 \%$ & $16,33.4 \%$ & I & / & I & I \\
\hline \multirow[t]{2}{*}{1999} & Yano [8] & 19 & $17,89.5 \%$ & $15,78.9 \%$ & $14,73.7 \%$ & $13,68.4 \%$ & I & I & 1 & I \\
\hline & & 21 & $20,95.2 \%$ & $18,85.7 \%$ & $16,76.2 \%$ & $13,61.9 \%$ & I & / & I & I \\
\hline \multirow[t]{2}{*}{2008} & $\mathrm{Wu}[9]$ & 29 & $20,69.0 \%$ & $8,27.6 \%$ & I & I & $2,6.9 \%$ & I & $13,44.8 \%$ & $26,89.7 \%$ \\
\hline & & 30 & $14,46.7 \%$ & $4,13.3 \%$ & / & I & $1,3.3 \%$ & / & $13,43.3 \%$ & $20,65.5 \%$ \\
\hline \multirow[t]{2}{*}{2009} & $\mathrm{Li}[10]$ & 42 & $41,97.6 \%$ & $40,94.7 \%$ & $40,94.7 \%$ & I & $41,97.6 \%$ & $32,76.2 \%$ & I & I \\
\hline & & 42 & $35,83.3 \%$ & $33,78.8 \%$ & $32,76.2 \%$ & I & $34,81.0 \%$ & $27,64.3 \%$ & I & I \\
\hline \multirow[t]{2}{*}{2011} & Zhong [11] & 14 & $9,64.3 \%$ & $7,49.8 \%$ & $3,21.4 \%$ & I & I & I & l & I \\
\hline & & 14 & $6,42.8 \%$ & $4,28.5 \%$ & $1,7.1 \%$ & I & I & / & I & I \\
\hline \multirow[t]{2}{*}{2012} & Iwai [12] & 132 & $95,72.0 \%$ & $55,41.9 \%$ & $32,24.2 \%$ & $13,9.8 \%$ & I & / & I & I \\
\hline & & 207 & $124,60.0 \%$ & $77,37.1 \%$ & $50,24.2 \%$ & $33,16.0 \%$ & I & I & I & I \\
\hline \multirow[t]{2}{*}{2012} & $\operatorname{Li}[13]$ & 87 & $78,89.7 \%$ & $65,74.7 \%$ & $52,59.8 \%$ & $26,29.9 \%$ & $63,72.4 \%$ & $45,51.7 \%$ & I & I \\
\hline & & 87 & $58,66.7 \%$ & $38,43.7 \%$ & $34,39.1 \%$ & $16,18.4 \%$ & $44,50.6 \%$ & $32,36.8 \%$ & I & I \\
\hline \multirow[t]{2}{*}{2013} & Yang [14] & 61 & $35,57.2 \%$ & $16,27.0 \%$ & I & I & I & I & $11,18.0 \%$ & $42,68.9 \%$ \\
\hline & & 61 & $23,37.3 \%$ & $7,10.1 \%$ & I & / & / & / & $10,16.4 \%$ & $30,49.2 \%$ \\
\hline \multirow[t]{2}{*}{2014} & Zhong [15] & 30 & $19,63.3 \%$ & $9,30.0 \%$ & $7,23.3 \%$ & I & I & / & $5,16.7 \%$ & $21,70.0 \%$ \\
\hline & & 30 & $18,60.0 \%$ & $7,21.7 \%$ & $4,13.3 \%$ & I & I & / & $6,20.0 \%$ & $21,70.0 \%$ \\
\hline \multirow[t]{2}{*}{2014} & Zhao [16] & 79 & $73,92.4 \%$ & $55,69.6 \%$ & $46,58.2 \%$ & I & I & I & I & I \\
\hline & & 78 & $62,79.5 \%$ & $43,55.1 \%$ & $29,37.2 \%$ & I & I & I & I & I \\
\hline \multirow[t]{2}{*}{2014} & Shi [17] & 28 & $6,21.4 \%$ & I & I & I & I & / & I & I \\
\hline & & 26 & $4,15.4 \%$ & / & / & I & I & / & I & I \\
\hline \multirow[t]{2}{*}{2015} & Kimura [18] & 50 & $49,98.0 \%$ & $47,94.0 \%$ & / & $41,81.4 \%$ & $45,90.0 \%$ & $35,70.0 \%$ & I & I \\
\hline & & 51 & $48,94.1 \%$ & $34,66.7 \%$ & / & $25,48.3 \%$ & $32,62.7 \%$ & $15,29.4 \%$ & / & 1 \\
\hline \multirow[t]{2}{*}{2016} & Zhang [19] & 21 & $16,76.2 \%$ & I & I & I & $8,38.1 \%$ & / & $10,47.6 \%$ & $19,90.5 \%$ \\
\hline & & 61 & $36,59.0 \%$ & I & / & 1 & $12,19.7 \%$ & I & $15,24.6 \%$ & $54,88.5 \%$ \\
\hline
\end{tabular}

\section{DISCUSSION}

In our meta-analysis, we evaluated the efficacy of AIT for NSCLC, particularly in terms of the OS, PFS, ORR, and DCR. The final results showed that AIT could significantly improve the OS and PFS, although it had a relatively minor effect on the ORR and DCR. In the subgroup analysis, DC/CIK and CIK rather than LAK plus IL-2 significantly improved the 1-year and 2-year OS, most of individual subgroup was consistent with the primary outcome. Publication bias and sensitivity analyses helped evaluate the heterogeneity between studies. Our research was meaningful because we inferred the prognosis of NSCLC patients with a stable condition from the overall outcome, and the OS and PFS were found to be significantly improved. AIT has major potential in clinical cancer treatment, which is an important characteristic of tumor immunotherapy, and the present study provides fundamental data based on which future tumor immunotherapy research can be conducted.

At present, immunotherapy is the fourth most common type of anti-tumor therapy, following surgery, radiotherapy, and chemotherapy. The European Organization of Research and Treatment of Cancer classified biological therapy of tumors as cytokine therapy, antibody therapy, vaccine therapy, and gene therapy [21]. The origins and effects of different effector cells differ. In particular, IL-2 is a cytokine that serves as a growth factor of all $\mathrm{T}$ cell subsets, and has a wide range of biological activities, including the promotion of $\mathrm{B}$ cell proliferation. IL-2 is also involved in immune responses, antibody reactions, and tumor immune surveillance [22]. High 
Table 3: Quality criteria and risk of bias

\begin{tabular}{lccc}
\hline & $\begin{array}{c}\text { Low risk of bias } \\
\text { No. (\%) }\end{array}$ & $\begin{array}{c}\text { High risk of bias } \\
\text { No. (\%) }\end{array}$ & $\begin{array}{c}\text { Unclear risk of bias } \\
\text { No. (\%) }\end{array}$ \\
\hline $\begin{array}{l}\text { Power calculation of adoptive } \\
\text { immunotherapy therapy }\end{array}$ & $15(100)$ & $0(0)$ & $0(0)$ \\
$\begin{array}{l}\text { No conflicts of interest, funding } \\
\text { Risk of bias assessments }\end{array}$ & $11(73.3)$ & $0(0)$ & $4(26.7)$ \\
Random sequence generation & & & \\
Allocation concealment & $9(69.2)$ & $2(15.4)$ & $2(15.4)$ \\
Blinding of participants and personnel & $7(53.8)$ & $0(0)$ & $6(46.2)$ \\
Blinding of outcome assessment & $5(38.5)$ & $2(15.4)$ & $6(46.1)$ \\
Incomplete outcome data & $8(61.5)$ & $0(0)$ & $5(38.5)$ \\
Selective reporting & $11(84.6)$ & $0(0)$ & $2(15.4)$ \\
Other bias & $12(92.3)$ & $0(0)$ & $1(7.7)$ \\
\hline
\end{tabular}

aRisk of bias assessments was base on "Cochrane risk of bias tool".

\begin{tabular}{|c|c|c|c|c|c|c|c|c|c|c|}
\hline & \multirow[t]{2}{*}{ Study $^{b}$} & \multicolumn{4}{|c|}{ Selection } & \multirow[b]{2}{*}{ Comparability } & \multicolumn{3}{|c|}{ Outcome } & \multirow{2}{*}{$\begin{array}{l}\text { Total } \\
\text { score }\end{array}$} \\
\hline & & $\begin{array}{l}\text { Exposed } \\
\text { cohort }\end{array}$ & $\begin{array}{l}\text { Nonexposed } \\
\text { cohort }\end{array}$ & $\begin{array}{l}\text { Ascertainment } \\
\text { of exposure }\end{array}$ & $\begin{array}{l}\text { Outcome of } \\
\text { interest }\end{array}$ & & $\begin{array}{l}\text { Assessment } \\
\text { of outcome }\end{array}$ & $\begin{array}{l}\text { Length of } \\
\text { follow-up }\end{array}$ & $\begin{array}{l}\text { Adequacy of } \\
\text { follow-up }\end{array}$ & \\
\hline 2012 & Iwai & * & * & $*$ & * & $* *$ & * & * & $*$ & 9 \\
\hline 2013 & Yang & * & $*$ & $*$ & $*$ & ** & * & & & 7 \\
\hline
\end{tabular}

"Risk of bias assessments was base on "the Newcastle-Ottawa Scale (NOS)".

doses of IL-2 and other cytokines stimulate the peripheral blood lymphocytes to transform into LAK, which can kill tumor cells insensitive to NK [23]. TIL are infiltrating lymphocytes isolated from tumor tissue. Following intervention with IL-2 and CD3, TIL are activated and transformed into tumor-specific lymphocytes or NK [24]. CIK is a new type of immunocompetent cell that has been termed as an NK-like $\mathrm{T}(\mathrm{NK} / \mathrm{T})$ lymphocyte due to their

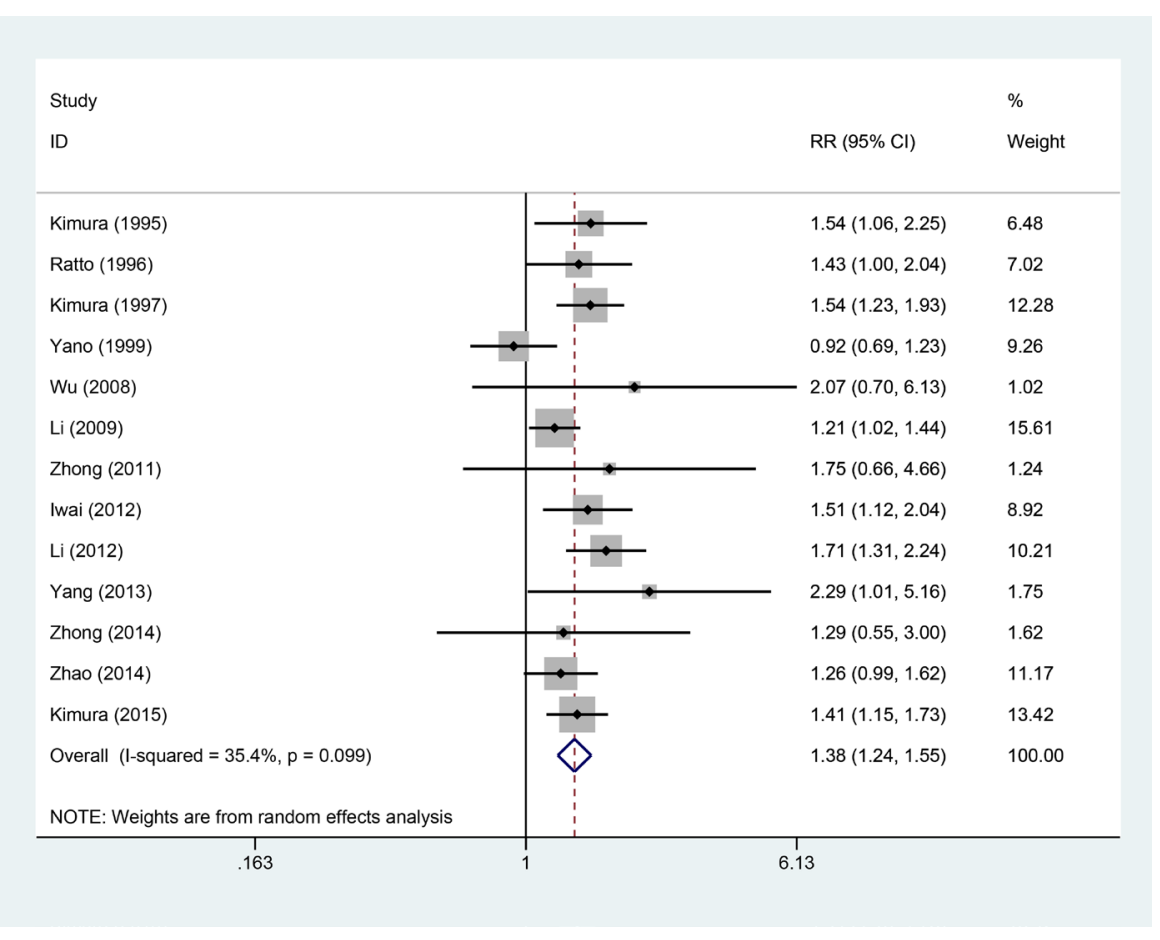

Figure 3: Two-year OS between the AIT and CT groups. 
Table 4: The outcome of subgroup analysis of AIT versus CT in relation of 1-year OS and 2-year OS

\begin{tabular}{|c|c|c|c|c|c|c|c|c|}
\hline \multirow[b]{2}{*}{ Group } & \multicolumn{4}{|c|}{ 1-year OS } & \multicolumn{3}{|c|}{ 2-year OS } & \multirow[b]{2}{*}{$\begin{array}{l}I^{2} \\
(\%)\end{array}$} \\
\hline & $\begin{array}{l}\text { No.of } \\
\text { studies }\end{array}$ & RR $(95 \%$ CI $)$ & $P$ heterogeneity & $\begin{array}{l}I^{2} \\
(\%)\end{array}$ & $\begin{array}{l}\text { No.of } \\
\text { studies }\end{array}$ & RR (95\% CI) & $P$ heterogeneity & \\
\hline Total & 15 & $1.16(1.06-1.26)$ & 0.001 & 62.9 & 13 & $1.38(1.23-1.55)$ & 0.099 & 35.4 \\
\hline \multicolumn{9}{|l|}{ Effector cell } \\
\hline Total & 12 & & & & 10 & & & \\
\hline $\mathrm{LAK}+\mathrm{IL}-2$ & 3 & $1.02(0.86-1.21)$ & 0.027 & 72.3 & 3 & $1.30(0.90-1.86)$ & 0.011 & 78.0 \\
\hline CIK & 2 & $1.36(1.16-1.59)$ & 0.693 & 0 & 2 & $1.73(1.33-2.24)$ & 0.734 & 0 \\
\hline DC/CIK & 7 & $1.19(1.09-1.30)$ & 0.751 & 0 & 5 & $1.26(1.10-1.44)$ & 0.471 & 0 \\
\hline \multicolumn{9}{|l|}{ Cycle } \\
\hline Total & 12 & & & & 11 & & & \\
\hline$>4$ & 8 & $1.18(1.04-1.33)$ & $<0.001$ & 75.5 & 7 & $1.52(1.36-1.49)$ & 0.939 & 0 \\
\hline$\leq 4$ & 4 & $1.19(1.08-1.31)$ & 0.376 & 3.4 & 4 & $1.28(1.07-1.52)$ & 0.305 & 17.5 \\
\hline \multicolumn{9}{|l|}{ Nationality } \\
\hline Total & 14 & & & & & & & \\
\hline China & 10 & $1.20(1.08-1.33)$ & 0.096 & 39.3 & 7 & $1.41(1.17-1.70)$ & 0.166 & 34.4 \\
\hline Japan & 4 & $1.08(0.96-1.22)$ & 0.010 & 73.5 & 5 & $1.36(1.13-1.65)$ & 0.046 & 58.8 \\
\hline
\end{tabular}

expression of CD3 and CD56 membrane proteins. CIK not only have the potent antitumor effects of $\mathrm{T}$ lymphocytes, but also possess the MHC-unrestricted cytotoxicity of NK [25]. Moreover, dendritic cells (DC) are potent antigenpresenting cells that can effectively resist the immune escape of tumor cells. Co-culturing tumor antigensensitized DC with CIK helps generate DC-activated CIK $(\mathrm{DC} / \mathrm{CIK})$, which promotes the maturation of $\mathrm{DC}$ and proliferation of CIK and increases the levels of cytokines (IFN, TNF, and CSF), without any side-effects, as those associated with CIK or MHC-unrestricted cytotoxicity in NK [26]. In fact, DC/CIK show a more profound antitumor effect, as compared with other effector cells, and are currently widely used in AIT for various cancers.

The administration of TIL in NSCLC patients helps prolong overall survival time duration to a greater extent,

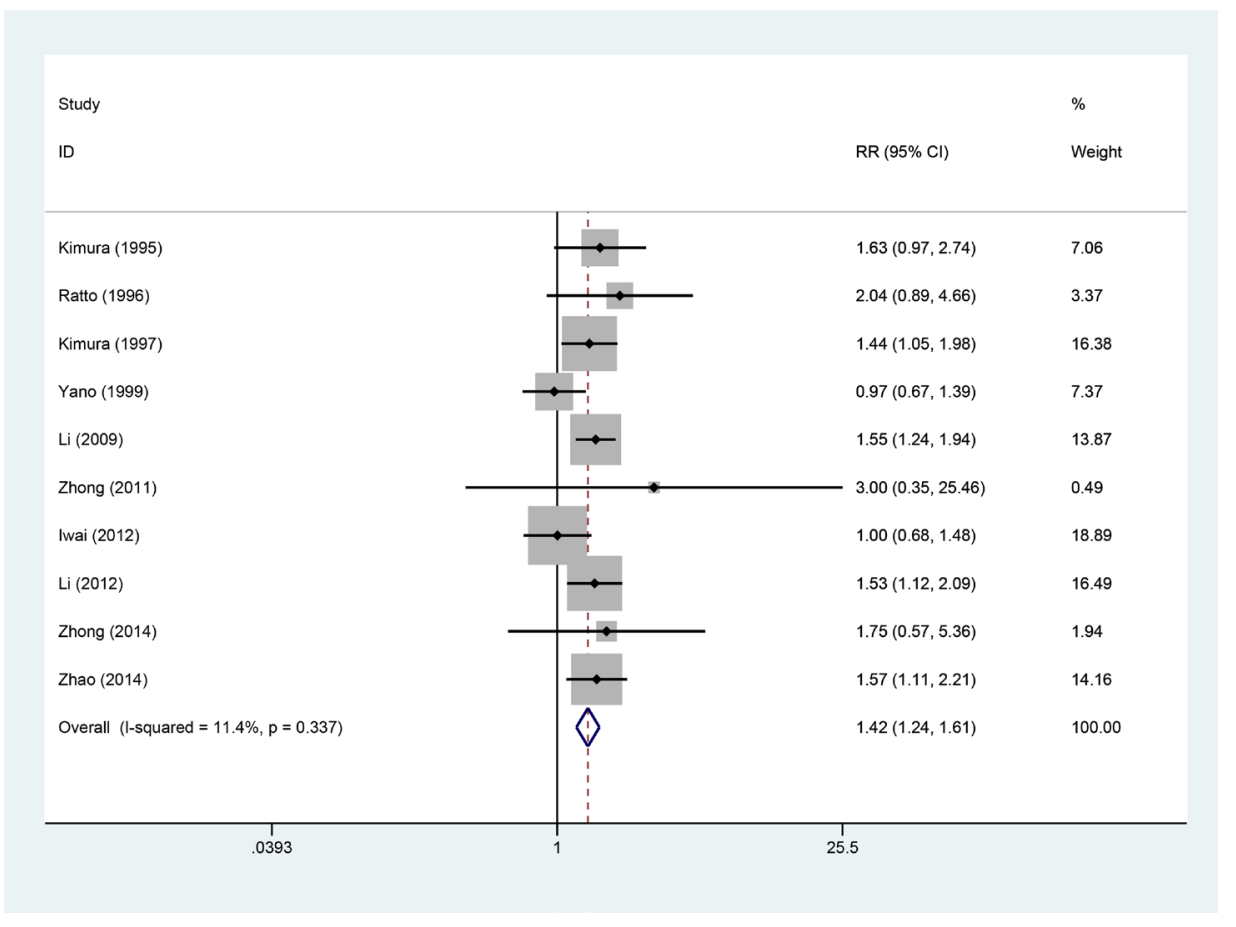

Figure 4: Three-year OS between the AIT and CT groups. 
as compared to chemotherapy or radiotherapy, and $80 \%$ of patients do not report any severe adverse effects during treatment [6]. Recent studies showed that increasing the levels of CD8-positive TIL could represent a more potent treatment for melanoma [27]. In fact, CD137 may have the same role as CD8, and can help administrate TIL therapy for NSCLC [28]. $\gamma \delta$ T cells regarded as another type of effector cell, belong to the T lymphocyte family, and account for approximately $5 \%$ of peripheral blood $\mathrm{T}$ cells. Antibody-expanded $\gamma \delta \mathrm{T}$ cells generating more effector T cells may release greater amounts of cytokine, and may immediately induce cytotoxicity functions [29]. Hanagiri [30] et al. stated that, when $\gamma \delta$ T cells expressed specific $\alpha \beta$ TCR molecules in addition to $\gamma \delta$ TCR, they were more effective in NSCLC patients. NK are the innate effector cells of immune response to pathogens and cancer. Their phenotype is characterized by the expression of CD56 and an absence of CD3. Recent reports mentioned that targeted drugs, such as thalidomide or imatinib, could improve the levels of NK in the peripheral blood of NSCLC patients [31]. Moreover, CIK subsets contain regulatory $\mathrm{T}$ cells (Treg, CD4+ CD25+) that can suppress the immune function of the tumor. DC/CIK downregulate the inhibitory effect of Treg on the immune system of patients by reducing the levels of Treg in the CIK subsets. Furthermore, Zhao [32] et al. found that the average Th2 cytokine (IL-4, IL-10) levels were higher in NSCLC patients before immunotherapy, and hence, DC/ CIK could overcome the dominant status of Th2 cytokines and up-regulate the anti-tumor effect. Moreover, the researchers found that $\mathrm{DC} / \mathrm{CIK}$ induced rare side-effects in combination with chemotherapy. Shi [33] et al. believed that the synergistic anti-tumor efficacy of DC/CIK involved the normalization of the tumor vasculature and reduction in the hypoxic area in the tumor microenvironment.

An increasing number of studies are focusing on the tumor micro-environment. In particular, CTLA-4, PD-1, and PD-L1 blockade exhibited clinical benefits and good tolerance, with limited adverse effects [34, 35], although the actual effectiveness needs to be confirmed. Thus, it appears that AIT is effective and has limited side-effects, and is hence a useful treatment.

Zeng [36] included 4 RCTs in their small metaanalysis on the OS and adverse effects of AIT in NSCLC patients; in contrast, we included 15 high-quality studies in our meta-analysis, reported a more useful prognostic outcome, and provided a comprehensive and detailed description of the potential underlying AIT mechanism.

We found that DC/CIK yielded greater benefits and had a more potent cytotoxic function as compared with LAK in combination with IL-2 in subgroup analysis. As a result of the reduced side-effects, we believe that $\mathrm{DC} / \mathrm{CIK}$ vaccines can be considered in clinical practice, which may improve patient prognosis and quality of life. However, due to the strict culture conditions and timereliance inducing restrictions of $\mathrm{DC} / \mathrm{CIK}$, the cost of this treatment should be carefully reviewed and controlled prior to practical application. Consequently, further studies are needed to estimate the efficacy of the various treatment strategies for NSCLC.

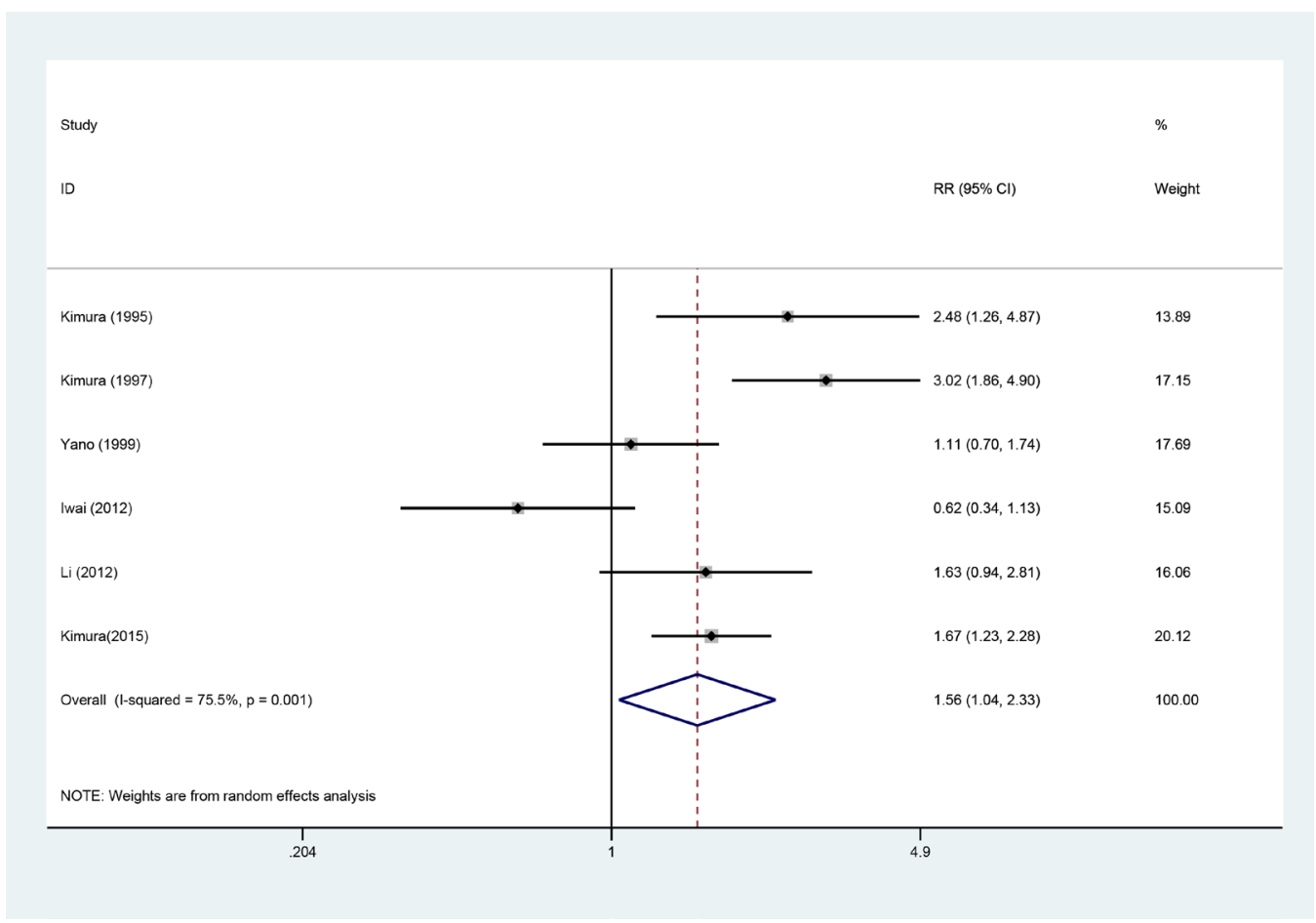

Figure 5: Five-year OS between the AIT and CT groups. 


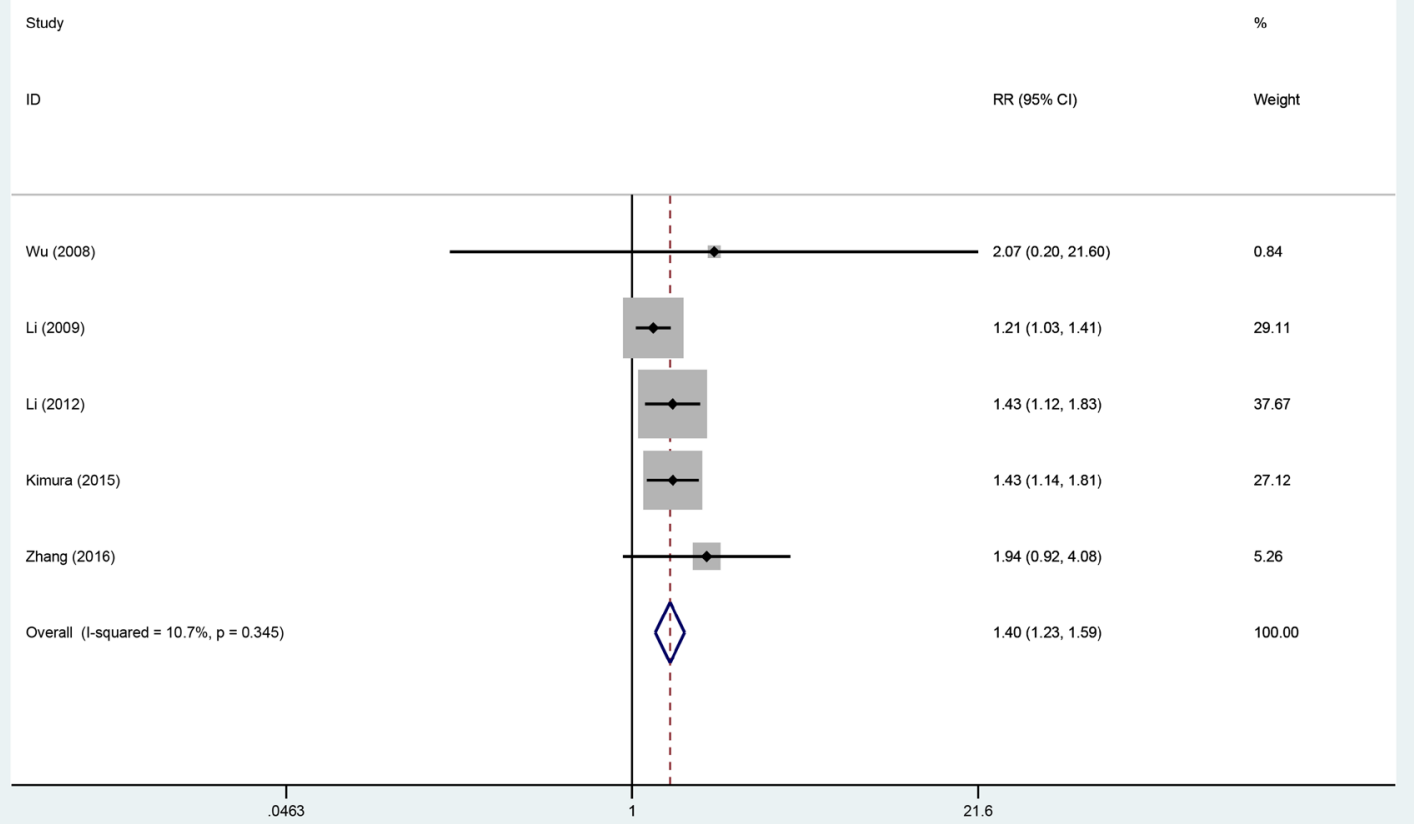

Figure 6: One-year PFS between the AIT and CT groups.

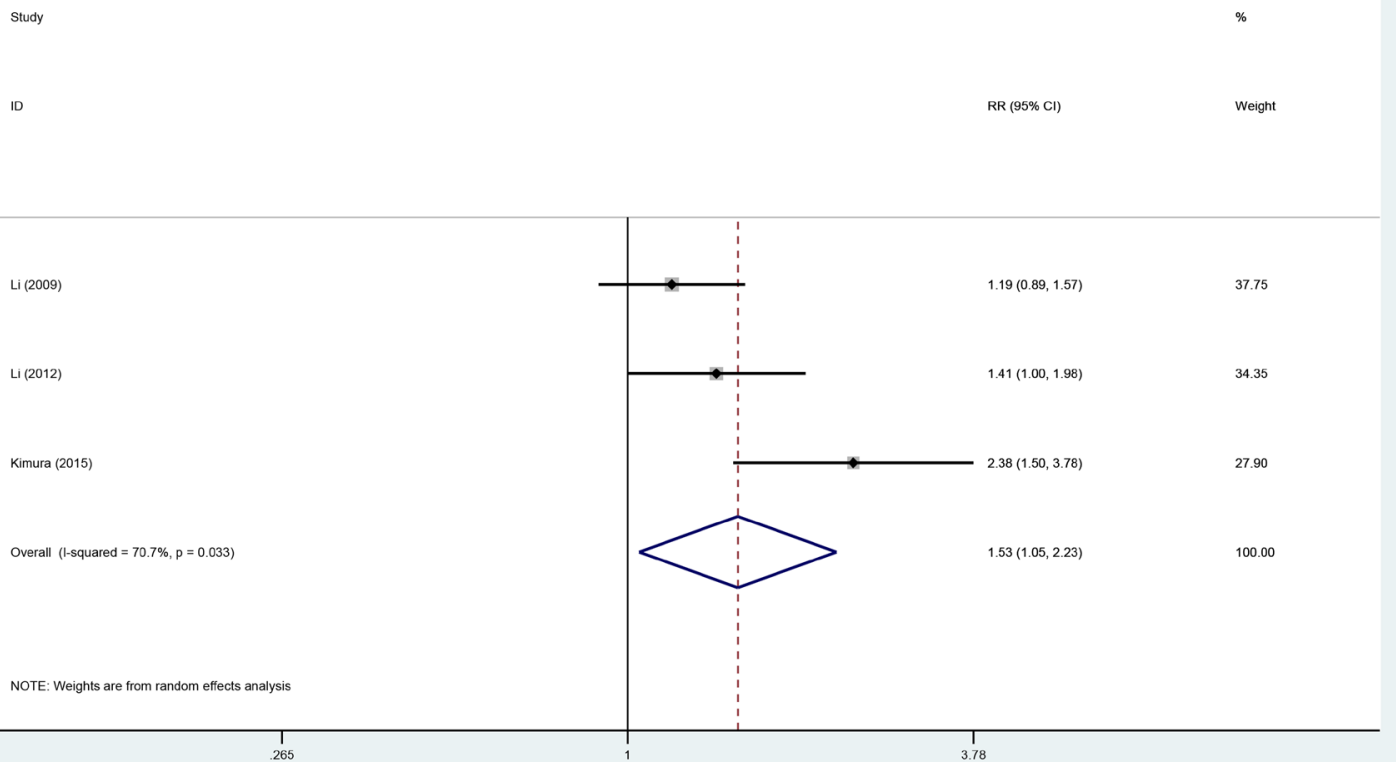

Figure 7: Two-year PFS between the AIT and CT groups. 
$\mathrm{RR}(95 \% \mathrm{Cl})$

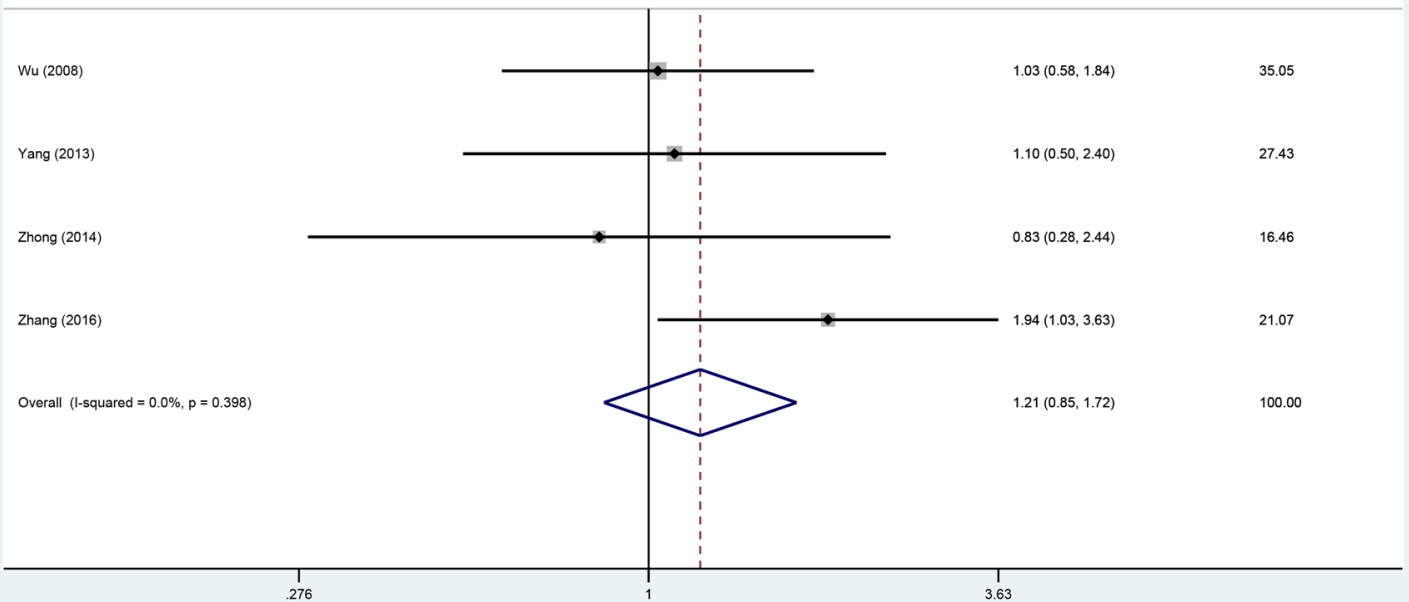

Figure 8: ORR between the AIT and CT groups.

Study

ID

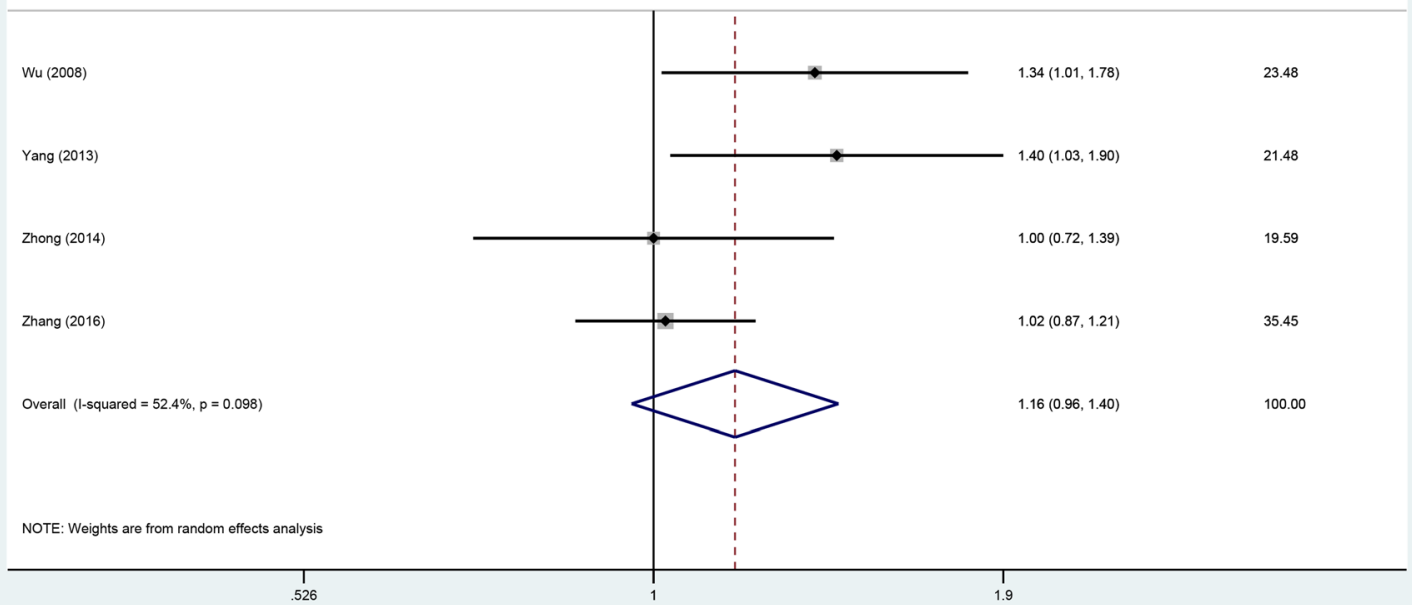

Figure 9: DCR between the AIT and CT groups. 
The results of our sensitivity and subgroup analyses were similar and robust. Our conclusion regarding most of the parameters (except DCR) was not significantly modified after excluding studies with high heterogeneity, and after conducting LAK plus IL-2 and DC/CIK strategies analysis. High heterogeneity was observed for 1-year OS, 2-year OS, 5-year OS, 2-year PFS, and DCR, and the main reasons for the heterogeneity included differences in drug regimens and individual differences. An insufficient number of patients was present in the high heterogeneity studies, and almost all these studies demonstrated a significant inverse association. Furthermore, compared with individual studies, the characteristics of studies design, clinical settings and patients differed in various aspects. For instance, the earliest research was conducted in 1995, whereas the latest study was conducted in 2016; during this period, marked progress had been made in detection technology. Some studies involved AIT with LAK in combination with IL-2, whereas the recent studies use DC/CIK. In addition to the variables studied in the previous study, other factors such as the patient population, tumor stage, type of pre-treatment, dosage and duration of AIT, treatment of the CT group, race differences, regional differences, and individual difference could lead to heterogeneity in the present study. However, the inclusion of 15 studies involving 1684 participants in our meta-analysis strengthened our ability to determine a significant association and provide a more reliable evaluation of AIT.

The present meta-analysis has certain limitations. First, the inclusion of additional studies led to an increase in the heterogeneity. Some indicators exhibited marked heterogeneity, which was inevitable due to the various factors involved. However, the heterogeneity has been

Begg's Test

adj. Kendall's Score $(P-Q)=25$

Std. Dev. of Score $=20.21$

Number of Studies $=15$

$z=1.24$

$\operatorname{Pr}>|z|=0.216$

$z=1.19$ (continuity corrected)

$\operatorname{Pr}>|z|=0.235$ (continuity corrected) explained in the meta-analysis. Second, the AIT cycles were not uniform, we could not determine the appropriate duration of AIT to maximize its effectiveness; this inhibits its application in clinical practice. Moreover, the reduced adverse effects with AIT were reported in only 4 trials $[10,15,17,19]$ (Table 5), the pooled result from these little sample sizes showed AIT had acceptable or even less toxicity compared with CT. Third, we did not include an adequate number of studies to yield credible results, and most of the studies were based on an Asian population, which could affect the final conclusion. Fourth, in 2 studies [8, 19], a random sequence of inclusion was not used as the patients could not afford AIT; in those cases, the researchers allowed the patients to choose appropriate therapies based on their circumstances. Finally, though there was no significant difference in clinical stage, histology, pre-treatment et al., these discordant elements might hinder us to draw final conclusion, we still needed more RCTs with consistent patients' conditions to help interpret our results. All the included studies only concentrated on AIT in combination with chemotherapy or radiotherapy versus $\mathrm{CT}$, and hence, it was difficult to estimate the efficacy of AIT alone. The efficacy of AIT was associated with patient age, race, smoking, alcoholism and heredity; therefore, further stratified analyses are needed on these indicators in the future. Due to discordance of AIT and CT, it is a future direction to compare specific AIT (LAK or TIL or DC/CIK) to specific CT (chemotherapy or radiotherapy or no adjuvant treatment (placebo)).

In conclusion, we observe that AIT has a significant role in NSCLC and the tolerability can be improved in AIT regimen. Even so additional studies with a large sample and high-quality RCTs are needed to validate these findings.

Egger's test

\begin{tabular}{r|rrrrrr}
\hline Std_Eff & Coef. & Std. Err. & $t$ & P>lt| & [958 Conf. Interval] \\
\hline slope & .0115192 & .0531848 & 0.22 & 0.832 & -.1033795 & .126418 \\
bias & 1.314713 & .6138832 & 2.14 & 0.052 & -.0115008 & 2.640927 \\
\hline
\end{tabular}

Figure 10: Begg's and Egger's test for 1-year OS. 
Table 5: Adverse effects of AIT reported in 4 included studies

\begin{tabular}{lcccccc}
\hline Adverse Events & $\begin{array}{c}\text { AdoptiveImmunotherapy } \\
\text { (events/total) }\end{array}$ & $\begin{array}{c}\text { Control Therapy } \\
\text { (events/total) }\end{array}$ & RR (95\% CI) & $\boldsymbol{P}$ value & \multicolumn{2}{c}{ Heterogeneity } \\
\cline { 5 - 7 } & & & & $\mathbf{I}^{\mathbf{2}} \mathbf{( \% )}$ & $\boldsymbol{P}$ value \\
\hline Fever [10, 17, 19] & $17 / 91$ & $44 / 129$ & $0.75(0.22-2.54)$ & 0.650 & 75.0 & 0.020 \\
Anemia [10,15, 17,] & $13 / 70$ & $20 / 68$ & $0.65(0.36-1.15)$ & 0.140 & 0 & 0.770 \\
Leucopenia [10, 15] & $53 / 72$ & $63 / 72$ & $0.84(0.71-0.99)$ & 0.040 & 38.0 & 0.200 \\
Nausea [10, 15, 19] & $35 / 93$ & $56 / 133$ & $0.71(0.54-0.92)$ & 0.010 & 0 & 0.840 \\
Rash [10, 15, 17] & $28 / 100$ & $60 / 98$ & $0.44(0.17-1.16)$ & 0.100 & 84.0 & 0.002 \\
Fatigue [10] & $3 / 42$ & $24 / 42$ & NA & NA & NA & NA \\
Diarrhea [17] & $9 / 28$ & $6 / 26$ & NA & NA & NA & NA \\
Thrombocytopenia [15] & $3 / 30$ & $4 / 30$ & NA & NA & NA & NA \\
Anorexia [19] & $3 / 21$ & $6 / 61$ & NA & NA & NA & NA \\
Allergy [19] & $1 / 21$ & $0 / 61$ & NA & NA & NA & NA \\
Myelosuppression [19] & $2 / 21$ & $8 / 61$ & NA & NA & NA & NA \\
Radiation pneumonitis [19] & $7 / 21$ & $11 / 61$ & NA & NA & NA & NA \\
\hline
\end{tabular}

${ }^{a}$ no available statistical data.

\section{MATERIALS AND METHODS}

This systematic review and meta-analysis was conducted in accordance with the PRISMA guidelines (Supplementary Table 1) and has been registered in PROSPERO (CRD42017060172).

\section{Search strategy}

Parallel randomized controlled trials (RCTs) and high-quality observational studies that compared AIT with control therapies (CT) in NSCLC patients were collected. We systematically searched PubMed, the Cochrane Library, EMBASE, Medline, and Web of Science, from the time of inception of each database to February 31, 2017, without any language restrictions. We used the following combined text and MeSH terms: "Carcinoma, Non-Small Cell Lung" and "Immunotherapy, Adoptive Cellular". The complete search terms for Pubmed included: (Carcinoma, NonSmall-Cell Lung [MeSH Terms] OR Carcinoma, Non Small Cell Lung [Text Word] OR Carcinomas, Non-Small-Cell Lung [Text Word] OR Lung Carcinoma, Non-Small-Cell [Text Word] OR Lung Carcinomas, Non-Small-Cell [Text Word] OR Non-Small-Cell Lung Carcinomas [Text Word] AND (Immunotherapy, Adoptive Cellular [MeSH Terms] OR Adoptive Immunotherapy [Text Word] OR Adoptive Immunotherapies [Text Word] OR Immunotherapies, Adoptive [Text Word] OR Cellular Immunotherapy, Adoptive [Text Word]). We collected the studies in accordance with the requirements in various possible ways.

\section{Study selection}

We included studies that met all the following conditions: (a) Patients: adult patients with NSCLC diagnosed via imaging, pathology examination, or other adjuvant diagnosis based on the WHO criteria. Patient inclusion was not restricted based on sex, race, or nationality, and pre-treatment (surgery, chemotherapy, or radiotherapy) was allowed to ensure that they were suitable candidates for immunotherapy; (b) Intervention: AIT or AIT plus adjuvant therapy; (c) Comparison: chemotherapy, radiotherapy, adjuvant methods, plus different doses/durations of immunotherapy, or placebo; (d) Outcome: OS or progression-free survival rate (PFS) or the objective response rate (ORR) or disease control rate (DCR); (e) Design: RCTs and observational studies (prospective or retrospective cohort studies). The proportion of cases that were lost to follow-up, that withdrew from the study, or that encountered unexpected conditions did not exceed $20 \%$. The patients' clinical stage, histology, sex, age, pre-treatment existed no significant difference and was comparable among groups.

The most complete and novel reports were included for data extraction and assessment, if the objects were duplicated. Reviews without original data, case reports, meta-analyses, letters, expert opinions, and animal studies were excluded.

\section{Data extraction}

Two independent investigators reviewed the research titles and abstracts, and the eligible studies were then retrieved for full-text assessments. The assessments of exposure and outcome, duration of follow-up, and statistical control for potential confounding factors were conducted by 2 investigators via consensus; disagreements were resolved by a third investigator.

We extracted the following useful data from the studies: total number of participants, region, 
immunotherapy, control therapies, duration. We then estimated the OS, PFS, ORR, and DCR of the patients, which was pooled through relative risk (RR). If these indicators could not be directly obtained, we inferred the values from the individual data curves presented in the studies. We also reviewed the adverse effects of AIT specified in the included studies.

\section{Quality assessments}

Two reviewers assessed the risk of corresponding bias using the "Cochrane risk of bias tool" for each RCT. Observational studies were evaluated using the NewcastleOttawa Scale (NOS) [20]. Moreover, the reporting and ascertainment of included strains, the statistical power, and the funding and potential for conflict of interest associated with individual trials were assessed.

\section{Statistical analysis}

We evaluated the efficacy of AIT based on the following 4 indicators: OS, PFS, ORR, and DCR. The $\mathrm{RR}$ and $95 \% \mathrm{CI}$ of all the indicators were recorded; the hazard ratios (HR) and incidence rate ratios were directly considered as the RR. The homogeneity of the effect size across studies was tested using Q statistics (at the $P<0.10$ level of significance). We also calculated the $\mathrm{I}^{2}$ statistic to help assess heterogeneity (high heterogeneity $>50 \%$; low heterogeneity, $<50 \%$ ). Data were analyzed using fixedeffects models when $P>0.10$ for the Q statistic; in other cases, random-effects models were used [37]. For the meta-analysis of each outcome, we conducted pre-planned sensitivity analyses restricted to trials that included the efficacy of AIT. We also conducted pre-specified subgroup analyses based on the type of effector cells used, patient nationality, cycles of AIT, and the effect of these variables on outcome.

The presence of potential publication bias was assessed using Begg's funnel plots test [38] and Egger's regression test [39]. All statistical analyses were performed with Stata 12.0 ; a $P$ value $<0.05$ was considered to be significant, except where otherwise specified.

\section{Abbreviations}

AIT: Adoptive immunotherapy; CT: Control therapy; NSCLC: Non-small cell lung cancer; RCTs: Randomised controlled trials; OS: Overall survival rate; PFS: Progression-free survival rate; ORR: Objective response rate; DCR: Disease control rate; RR: Relative risk; 95\%CI: 95\% Confidence intervals; NK: Natural killer cells; CTL: Cytotoxic T lymphocytes; LAK: Lymphocytes activated killer cells; CIK: Cytokine-induced killer cells; DC: Dentritic cells; TIL: Tumor infiltrating lymphocytes; NKT: NK like lymphocytes; AKT: Activated killer T cells; PRISMA: Preferred Reporting Items for Systematic Review and Meta-Analysis; PROSPERO: International Prospective Register of Systematic Reviews; IL-2: Interleukin 2; IFN: Interferon; CSF: Colony stimulating factor; PD-1: Programmed death 1; PD-L1: Programmed death-ligand 1; CTLA-4: Cytotoxic T lymphocyte-associated antigen-4.

\section{Authors' contributions}

Binghao Zhao conceived of the idea, designed the study, contributed to search the relevant database. Wenxiong Zhang interpreted the data and performed the study through STATA. Binghao Zhao, Wenxiong Zhang, Dongliang Yu helped interpret the data and other relevant information. Jiangjun $\mathrm{Xu}$ contributed to analyze quality of each study and confirmed statistical analyses. Yiping Wei provided the examination for the methodology and reviewed our manuscript.

\section{ACKNOWLEDGMENTS}

The authors would like to thank Dr. Jinhua Peng for the data collection, Professor Yanhua Tang for her advice, and all the patients who participated in this study.

\section{CONFLICTS OF INTEREST}

All authors declare no conflicts of interest.

\section{FUNDING}

This study was supported by National Natural Science Foundation of China (NSFC), with no commercial entity involved, number of grants (81560345).

\section{REFERENCES}

1. Sibille A, Paulus A, Martin M, Bourhaba M, Barthelemy N, Radermecker M, Corhay JL, Louis R, Duysinx B. [MANAGEMENT OF NON-SMALL CELL LUNG CANCER]. [Article in French]. Rev Med Liege. 2015; 70:432-441.

2. Nascimento AV, Bousbaa H, Ferreira D, Sarmento B. NonSmall Cell Lung Carcinoma: An Overview on Targeted Therapy. Curr Drug Targets. 2015; 16:1448-1463.

3. Reinmuth N, Heigener DF, Reck M. [Non-small cell lung cancer: news from immunotherapy]. [Article in German]. Deut Med Wochenschr. 2015; 140:329-333.

4. Mayor M, Yang N, Sterman D, Jones DR, Adusumilli PS. Immunotherapy for non-small cell lung cancer: current concepts and clinical trials. EurJ Cardio-Thorac. 2016; 49:1324.

5. Kimura H, Yamaguchi Y. Adjuvant immunotherapy with interleukin 2 and lymphokine-activated killer cells after noncurative resection of primary lung cancer. Lung Cancer. 1995; 13:31-44. 
6. Ratto GB, Zino P, Mirabelli S, Minuti P, Aquilina R, Fantino G, Spessa E, Ponte M, Bruzzi P, Melioli G. A randomized trial of adoptive immunotherapy with tumorinfiltrating lymphocytes and interleukin-2 versus standard therapy in the postoperative treatment of resected nonsmall cell lung carcinoma. Cancer. 1996; 78:244-251.

7. Kimura H, Yamaguchi Y. A phase III randomized study of interleukin-2 lymphokine-activated killer cell immunotherapy combined with chemotherapy or radiotherapy after curative or noncurative resection of primary lung carcinoma. Cancer. 1997; 80:42-49.

8. Yano T, Sugio K, Yamazaki K, Kase S, Yamaguchi M, Ondo K, Yoshino I, Sugimachi K. Postoperative adjuvant adoptive immunotherapy with lymph node-LAK cells and IL-2 for pathologic stage I non-small cell lung cancer. Lung Cancer. 1999; 26:143-148.

9. Wu C, Jiang J, Shi L, Xu N. Prospective study of chemotherapy in combination with cytokine-induced killer cells in patients suffering from advanced non-small cell lung cancer. Anticancer Res. 2008; 28:3997-4002.

10. Li H, Wang C, Yu J, Cao S, Wei F, Zhang W, Han Y, Ren XB. Dendritic cell-activated cytokine-induced killer cells enhance the anti-tumor effect of chemotherapy on nonsmall cell lung cancer in patients after surgery. Cytotherapy. 2009; 11:1076-1083.

11. Zhong R, Teng J, Han B, Zhong H. Dendritic cells combining with cytokine-induced killer cells synergize chemotherapy in patients with late-stage non-small cell lung cancer. Cancer Immunol Immunother. 2011; 60:1497-1502.

12. Iwai K, Soejima K, Kudoh S, Umezato Y, Kaneko T, Yoshimori K, Tokuda H, Yamaguchi T, Mizoo A, Setoguchi Y, Kamigaki T, Fujimoto K, Goto S. Extended survival observed in adoptive activated $\mathrm{T}$ lymphocyte immunotherapy for advanced lung cancer: results of a multicenter historical cohort study. Cancer Immunol Immunother. 2012; 61:1781-1790.

13. Li R, Wang C, Liu L, Du C, Cao S, Yu J, Wang SE, Hao X, Ren X, Li H. Autologous cytokine-induced killer cell immunotherapy in lung cancer: a phase II clinical study. Cancer Immunol Immunother. 2012; 61:2125-2133.

14. Yang L, Ren B, Li H, Yu J, Cao S, Hao X, Ren X. Enhanced antitumor effects of DC-activated CIKs to chemotherapy treatment in a single cohort of advanced non-small-cell lung cancer patients. Cancer Immunol Immunother. 2013; 62:65-73.

15. Zhong R, Han B, Zhong H. A prospective study of the efficacy of a combination of autologous dendritic cells, cytokine-induced killer cells, and chemotherapy in advanced non-small cell lung cancer patients. Tumor Biol. 2014; 35:987-994.

16. Zhao M, Hongbing LI, Lei LI, Zhang Y. Effects of a gemcitabine plus platinum regimen combined with a dendritic cell-cytokine induced killer immunotherapy on recurrence and survival rate of non-small cell lung cancer patients. Exp Ther Med. 2014; 7:1403-1407.
17. Shi SB, Tang XY, Tian J, Chang CX, Li P, Qi JL. Efficacy of erlotinib plus dendritic cells and cytokine-induced killer cells in maintenance therapy of advanced non-small cell lung cancer. J Immunother. 2014; 37:250-255.

18. Kimura H, Matsui Y, Ishikawa A, Nakajima T, Yoshino M, Sakairi Y. Randomized controlled phase III trial of adjuvant chemo-immunotherapy with activated killer $\mathrm{T}$ cells and dendritic cells in patients with resected primary lung cancer. Cancer Immunol Immunother. 2015; 64:51-59.

19. Zhang L, Xu Y, Shen J, He F, Zhang D, Chen Z, Duan Y, Sun J. Feasibility study of DCs/CIKs combined with thoracic radiotherapy for patients with locally advanced or metastatic non-small-cell lung cancer. Radiat Oncol. 2016; 11:1-8.

20. Higgins JP, Green S. Cochrane Handbook for Systematic Reviews of Interventions. N-S Aech Ex Path Ph. 2010; 2011:S38.

21. Zwierzina H. Biological therapy - where do we stand? Eur J Cancer. 1999; 35:S1-S3.

22. Motohashi S, Nagato K, Kunii N, Yamamoto H, Yamasaki K, Okita K, Hanaoka H, Shimizu N, Suzuki M, Yoshino I. A phase I-II study of alpha-galactosylceramide-pulsed IL-2/ GM-CSF-cultured peripheral blood mononuclear cells in patients with advanced and recurrent non-small cell lung cancer. J Immunother. 2009; 182:2492.

23. Yano T, Sugio K, Yamazaki K, Kase S, Yamaguchi M, Ondo K, Yoshino I, Sugimachi K. Postoperative adjuvant adoptive immunotherapy with lymph node-LAK cells and IL-2 for pathologic stage I non-small cell lung cancer. Lung Cancer. 1999; 26:143-148.

24. Andersen MH, Straten P, Svane IM, Junker N. Ex vivo expansion and characterization of Tumor Infiltrating Lymphocytes from two distinct cancers-a common platform for future adoptive cell transfer therapy. Apmis. 2008; 116:431-431.

25. Schmeel LC, Schmeel FC, Coch C, Schmidt-Wolf IG. Cytokine-induced killer (CIK) cells in cancer immunotherapy: report of the international registry on CIK cells (IRCC). J Cancer Res Clin. 2015; 141:839-849.

26. Li DP, Li W, Feng J, Chen K, Tao M. Adjuvant chemotherapy with sequential cytokine-induced killer (CIK) cells in stage IB non-small cell lung cancer. Oncol Res. 2015; 22:67-74.

27. Dudley ME, Gross CA, Langhan MM, Garcia MR, Sherry RM, Yang JC, Phan GQ, Kammula US, Hughes MS, Citrin DE, Restifo NP, Wunderlich JR, Prieto PA, et al. CD8+ enriched "young" tumor infiltrating lymphocytes can mediate regression of metastatic melanoma. Clin Cancer Res. 2010; 16:6122-6131.

28. Ye Q, Song DG, Poussin M, Yamamoto T, Best A, Li C, Coukos G, Powell DJ Jr. CD137 accurately identifies and enriches for naturally occurring tumor-reactive $\mathrm{T}$ cells in tumor. Clin Cancer Res. 2014; 20:44-55.

29. Kang N, Zhou J, Zhang T, Wang L, Lu F, Cui Y, Cui L, $\mathrm{He}$ W. Adoptive immunotherapy of lung cancer with immobilized anti-TCRgammadelta antibody-expanded 
human gammadelta T-cells in peripheral blood. Canc Biol. 2009; 8:1540-1549.

30. Hanagiri T, Shigematsu Y, Kuroda K, Baba T, Shiota H, Ichiki Y, Nagata Y, Yasuda M, So T, Takenoyama M, Tanaka F. Antitumor activity of human gammadelta $\mathrm{T}$ cells transducted with CD8 and with T-cell receptors of tumor-specific cytotoxic T lymphocytes. Cancer Sci. 2012; 103:1414-1419.

31. Cheng M, Chen Y, Xiao W, Sun R, Tian Z. NK cell-based immunotherapy for malignant diseases. Cell Mol Immunol. 2013; 10:230-252.

32. Zhao P, Bu X, Wei X, Sun W, Xie X, Li C, Guo Q, Zhu D, Wei X, Gao D. Dendritic cell immunotherapy combined with cytokine-induced killer cells promotes skewing toward Th2 cytokine profile in patients with metastatic non-small cell lung cancer. Int Immunopharmacol. 2015; 25:450-456.

33. Shi S, Wang R, Chen Y, Song H, Chen L, Huang G. Combining antiangiogenic therapy with adoptive cell immunotherapy exerts better antitumor effects in non-small cell lung cancer models. PloS one. 2013; 8:e65757.

34. Demaria S, Kawashima N, Yang AM, Devitt ML, Babb JS, Allison JP, Formenti SC. Immune-mediated inhibition of metastases after treatment with local radiation and CTLA-4 blockade in a mouse model of breast cancer. Clin Cancer Res. 2005; 11:728-734.

35. Deng L, Liang H, Burnette B, Beckett M, Darga T, Weichselbaum RR, Fu YX. Irradiation and anti-PD-L1 treatment synergistically promote antitumor immunity in mice. J Clin Invest. 2014; 124:687-695.

36. Zeng Y, Ruan W, He J, Zhang J, Liang W, Chen Y, He Q, He J. Adoptive Immunotherapy in Postoperative NonSmall-Cell Lung Cancer: A Systematic Review and MetaAnalysis. PloS one. 2016; 11:e0162630.

37. Higgins JP, Thompson SG, Deeks JJ, Altman DG. Measuring inconsistency in meta-analyses. Brit Med J. 2003; 327:557-560.

38. Begg CB, Mazumdar M. Operating characteristics of a rank correlation test for publication bias. Biometrics. 1994; 50:1088.

39. Langhorne P. Bias in meta-analysis detected by a simple, graphical test. Prospectively identified trials could be used for comparison with meta-analyses. Bmj Clin Res. 1998; $316: 471$. 